\title{
High Performance Fabrics Using Nanocellulose
}

\author{
Eunjoo Shin ${ }^{1}$ and Soonmo Choi ${ }^{2 *}$ \\ ${ }^{1}$ Department of Organic Materials and Polymer Engineering, Dong-A University, Republic of Korea
}

${ }^{2}$ Regional Research Institute for Fiber \& Fashion Materials, Yeungnam University, Republic of Korea

*Corresponding author: Soonmo Choi, Regional Research Institute for Fiber \& Fashion Materials, Yeungnam University, 280 Daehak-ro, Gyeongsan 38541, Republic of Korea

submission:

\begin{abstract}
Cellulose is the most abundant biopolymer material, which is extensively distributed in plants, marine animals such as tunicates, fungi, bacteria. Nowdays, nanocellulose such as cellulose nanofibrils (CNFs), cellulose nanocrystals (CNCs), and cellulose nanowiskers (CNWs) have come into the spotlight as reinforcing fillers within nanocomposites including reinforced textile due to its low cost, abundant, light-weight, renewability as well as nano-scale dimension. This article has focused on the employment of cellulose nanomaterials in the preparation high performance fabrics. .

Keywords:Nanocellulose; Fabrics; Nanocomposites; Finished textiles; Reinforced textile
\end{abstract}

\section{Introduction}

The investigation into nanocomposites has been currently undergoing rapid growth in interdisciplinary field including materials science, textile engineering, and biomaterials. Especrially, many challenges of nanomaterials in textiles include nanocoated/ finished textiles, nanocomposite textile fiber materials, nanofiber textiles, and nano-based non-wovens. In nanocomposite fields for nanocellulose in textiles, need to improve the properties of cloth or fabric materials have been increasing for durable and functional apparel manufactured in a sustainable manner [1-3].

Cellulose has been employed in the paper, biomedical fields, and researched as reinforcement for polymer nanocomposites for about 150 years [4]. Recently, numerous studies have focused on the isolation and production of nanocellulose such as cellulose nanofibrils (CNFs), cellulose nanocrystals (CNCs), and cellulose nanowiskers (CNWs) acting as a biobased alternative within synthetic resins [5]. These materials are natural, abundant, renewable, bio-degradable, high in strength and low in weight, making them attractive for developing bio-based, more sustainable product solutions. From these points, this new nanomaterials have been used in broad ranges for industry, which is including structural plastics, smart coatings, cosmetics, pharmaceuticals, solar energy collection [6]. This chapter will focus primarily on studies about high performance fabrics using nanocellulose.

\section{Applications of nanocellulose for textile}

The deficiencies of other materials have led to the development of nanomaterials for next-generation functional fabrics and electronic textiles [7]. Nanocellulose is a promising material for producing low cost fully recyclable flexible paper electronic devices and systems due to desirable properties such as light weightness, stiffness, non-toxicity, transparency, low thermal expansion, gas impermeability and improved mechanical properties. Nanocellulose has been utilized to allow for controlled slow release functionalities of anti-microbials in hygiene textile products. Antimicrobial nanocellulose is under development for applications in wallpaper for hospitals; paper wipes; impregnated textiles; water filters; food packaging materials $[8,9]$.

The use of nanomaterials in textiles can allow for enhanced stain repellence, reduce static, and improve electrical conductivity to fibers without compromising their comfort and flexibility. Cellulose nanofibers are more absorbent than superabsorbent polymers (SAPs) and biodegradable [10]. More specifically, this article will show a study about the nanocellulose treatment of fabrics.

\section{High performance fabrics}

In these days, using of nanoparticles as fillers or crosslinking agent was focusing on improving cotton fabric. Cellulose nanowiskers (CNWs) is used most commonly to make such properties in remediation of some of the serious defects of easy care and permanent press cotton fabrics. Shaheen et al. [11] reported that new strategy for remediation of some of the serious defects of easy care and permanent press cotton and blend fabrics was suggested by virtue of using cellulose nanoparticles as reinforcement. And new conducting nanocellulose-based materials were shown through coating textile fabrics with conducting metals such as silver and copper nanoparticles was manufactured. The fabric samples were treated with CNW, CNW-PAAm copolymer, and NCEC (nano- 
sized carbamoylethyl cellulose whiskers). Performance properties of reinforced fabrics encompassing roughness, stiffness, abrasion, crease recovery, tensile strength and elongation at break depicted that, a significant enhancement in all properties for cotton samples treated with any of the nanocellulosic used. In general, these properties increased by increasing nanocellulose concentration regardless of the nanocellulose used. Not only the treatment with nanocellulose increased the mechanical properties of cotton fabrics, but also the handle was to be softer and stronger than untreated fabrics [11]. Oikonomou et al. [12] suggests a method to evaluate cellulose-surfactant interactions with increased detection sensitivity. The method is based on the use of cellulose nanocrystals (CNCs), which are rod-shaped nanoparticles in the form of $200 \mathrm{~nm}$ laths that are negatively charged and can be dispersed in bulk solutions. This technique developed could be exploited to rapidly assess the deposition efficiency of fabric conditioners on cotton by changing the amount and nature of chemicals in the formulations [12].

Also, BC (Bacterial cellulose) was used to restore vulnerable historic silk fabrics with degradable reinforcements by Wu et al. [13] the high crystallinity and elastic modulus of the abundant hydroxyl groups and BC formed good interfacial interaction between the $\mathrm{BC}$ and the silk matrix and improved the crystallinity, thermal stability and tensile strength of the restored samples. Therefore, the degradable, environmentally friendly, solvent-free material BC is a promising product for silk fabric restoration and other reinforcement applications [13]. Nanocellulose is similar in nature to cotton and is an attractive alternative to the synthetic polymers used today for canvas consolidation. Nechyporchuk et al. [5] showed different mechanical effect of cellulose nanofibrils (CNF), carboxymethylated cellulose nanofibrils (CCNF) and cellulose nanocrystals (CNC) as canvas consolidants. Nanocellulose has higher degree of crystallinity compared to canvas fibers, which may be a key towards long-term stability [5].

In addition, Chattopadhyay et al. [14] researched the effects of nanocellulose treatment on polyester fabric [14]. These nanoparticles have been applied to polyester fabric by padding technique and manifested the improved physical and thermal properties. The nanocellulose treatment also improved absorbency and enhanced the color strength of fabric dyed with direct dyes, which also improves the fastness towards soaping.

\section{Conclusion and Prospect}

Owing to nanocellulose's versatility including abundance, outstanding mechanical properties, low weight, biocompatibility, biodegradability, it has been provided as promising materials for nanocomposites. Nowdays, nanocomposite materials of cellulose and polymers have received great attention. The interest in cellulose-based nanocomposite comes from lightweight, high strength as well as increased stiffness composite materials. The nanocomposites have constantly found different applications, such as materials science, hybrid materials, textile engineering, surface engineering, and biomedical area. The rising adoption of nanocomposites has led to growth of demand for nanocellulosebased materials.

\section{Acknowledgement}

This research was supported by the Basic Science Research Program of the National Research Foundation of Korea (NRF) funded by the Ministry of Education (NRF-2016R1A6A3A11930280 and NRF-2015R1C1A2A01056027).

\section{References}

1. Dufresne A (2010) Processing of polymer nanocomposites reinforced with polysaccharide nanocrystals. Molecules 15(6): 4111-4128.

2. Azizi-Samir MAS, Alloin F, Dufresne A (2005) Review of recent research into cellulosic whiskers, their properties and their application in nanocomposite field. Biomacromolecules 6(2): 612-626.

3. Dufresne A (2006) Comparing the mechanical properties of high performances polymer nanocomposites from biological sources. Journal of nanoscience and nanotechnology 6(2): 322-330.

4. Yang KK, Wang XL, Wang YZ (2007) Progress in nanocomposite of biodegradable polymer. Journal of industrial and engineering chemistry 13(4): 485-500.

5. Nechyporchuk O, Kolman K, Bridarolli A, Odlyha M, Bozec L, et al. (2018) On the potential of using nanocellulose for consolidation of painting canvases. Carbohydrate Polymers 194: 161-169.

6. Eichhorn SJ (2011) Cellulose nanowiskers: promising materials for advanced applications. Soft Matter 7(2): 303-315.

7. Son D, Koo JH, Song JK, Kim JM, Lee MC, et al. (2015) Stretachable carbon nanotube charge-trap floating-gate memory and logic devices for wearable electronics. ACS Nano 9(5): 5585-5593.

8. Ataide JA, de Carvalho NM, de Araujo Rebelo M, Chaud MV, et al. (2017) Bacterial nanocellulse loaded with bromelain: Assessment of antimicrobial, antioxidant and physical chemical properties. Scientific Reports 7: 18031.

9. Sundaram J, Pant J, Goudie MJ, Mani S, Handa H (2016) Antimicrobial and physicochemical characterization of biodegradable, nitric oxidereleasing nanocellulose-chitosan packing membranes. J Agric Food chem 64(25): 5260-5266.

10. Kono H, Fujita S (2012) Biodegradable superabsorbent hydrogels derived from cellulose by esterification crosslinking with 1,2,3,4-butanetetracarboxylic dianhydride. Carbohydrate Polymers 87(4): 2582-2588.

11. Hebeish A, Farag S, Shaheen TI (2018) High performance fabrics via innovative reinforcement route suing cellulose nanoparticles. The Journal of the textile institute 109: 186-194.

12. Oikonomous EK, Mousseau F, Ghristov N, Crstobal G, Vacher A, et al. (2017) Fabric Softener-cellulose nanocrystal interaction: A model for assessing surfactant deposition on cotton. The Journal of Physical Chemistry B 121: 2299-2307.

13. Wua SQ, Li MY, Fang BS, Tong H (2012) Reinforcement of vulnerable historic silk fabrics with bacterial cellulose film and its light aging behavior. Carbohydrate Polymers 88(2): 496- 501.

14. Chattopadhyay DP, Patel BH (2016) Synthesis, characterization and application of nano cellulose for enhanced performance of textiles. Journal of Textile Science and Engineering 6: 248-255. 
Creative Commons Attribution 4.0 International License

For possible submissions Click Here
TTEFT

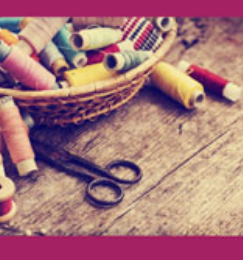

Trends in Textile Engineering \& Fashion Technology

\section{Benefits of Publishing with us}

- High-level peer review and editorial services

- Freely accessible online immediately upon publication

- Authors retain the copyright to their work

- Licensing it under a Creative Commons license

- Visibility through different online platforms 